\title{
Trend Is Your Friend, or Is It: Empirical Evidence from 60-Year US Stock Market Data
}

\author{
A. Teder, P. Sander, and T. Mitt
}

\begin{abstract}
The assumption of normality for the distribution of daily stock price returns is the core of the modern portfolio theory. This allows the correct estimation of Value at Risk. This paper performs a long term normality test for the market and finds that stock market returns are not in fact normally distributed, supported also by previous literature. We then analyze whether the distribution of daily returns for some period allows us to make predictions for a trend continuation by testing a simple strategy based on the distribution of previous daily returns. We find that by taking into account the previous trend one can achieve a much better risk-reward ratio while investing. This leads us to conclude that trends have much bigger importance in the market than it is currently recognized.
\end{abstract}

Index Terms-Stock market, trend continuation, normal distribution, price behavior.

\section{INTRODUCTION}

One of the main assumptions of modern portfolio theory (MPT) requires the daily historical returns of the stock market to be normally distributed [1]. In fact the normality of daily returns makes modern portfolio theory relevant since all the tools of MPT are thus applicable and the investor could constantly earn return similar to that of the market by exposing itself to a predetermined risk.

Furthermore the state of market efficiency where prices are derivatives of information available to investors [2] leads us to conclude that all future movements in the stock market are as random as the information that will come out in the future. Trendiness as such does not exist in efficient market hypothesis.

The long term trend of the stock market is explained by the Submartingale Model which states that if we assume that for all time and information the equilibrium expected returns are positive then one cannot have constantly greater expected profits by using some strategy than just buying-and-holding the market [3].

At the same time there are theories like the Dow Theory which assumes that prices move in trends [4] and by applying tools like the ones provided by technical analysis one can constantly have greater profits than the buy-and-hold strategy.

If prices moved in trends one could assume that positive returns are followed by more positive returns and negative returns are followed by more negative returns.

The following study focuses on testing the trendiness of the market by testing the distribution of daily returns on different time frames and analyzing whether buying the

Manuscript received December 25, 2013; revised March 31, 2014.

A. Teder and P. Sander are with the University of Tartu, Estonia (e-mail: allant@ut.ee). up-trend or selling the down-trend has any benefits whatsoever. In this study we define trend as a skewed distribution of returns. We assume that in an up-trend there are more days with a positive return and in a down-trend there are more days with a negative return.

If the markets were efficient in various timeframes we would assume that even in an uptrend the daily returns are normally distributed and the mean of the distribution would be positive. The same applies for a downtrend - the daily returns would be normally distributed and the mean of the distribution would be negative.

This leads us to the main research question of the current paper: are market movements indeed random and trends as such do not have any practical value for investing purposes? Also are daily returns normally distributed across different timeframes? If both these conditions are fulfilled then the one cannot constantly beat the market since market movements are mostly random and best results are achieved by tracking the market. However if both or one of these assumptions is incorrect in general on in some timeframes one has to apply tools different than those that form the modern portfolio theory.

\section{LITERATURE OVERVIEW}

Mandelbrot was the first researcher to suggest that stock market returns are better described by power law rather than the law of normality and that returns tend to be skewed. [5] His research was mostly ignored due to the complexity of skewed distributions [6]. This was later revisited by Fama, the author of the Efficient Market Hypothesis who concluded that monthly stock market returns were not best described by normal distribution. [7]. The same has been later confirmed by Teichmoeller [8] and Officer [9] who conclude that US stock market returns have much fatter tails than normal distribution would allow. Same is shown by Praetz [10] and Stadnik (also for Euro Bond futures, EUR/USD currency pair) [11].

Rachev, Stoyanov, Biglova and Fabozzi argue that the distribution of daily returns for US stocks is much better described with Paretian distribution (a type of power law probability distribution) rather than normal distribution [12]. Antoniou, Ivanov, Ivanov and Zrelov test various distributions and stocks (US and EU) and stock market indices (US) and conclude that stock price movements are by character much more complicated than simple normal or log-normal functions [13]. Katz and Tian conclude by analyzing daily returns of 520 US industrial companies' stocks that fat tails of returns are much more extreme than the usual normal distribution would allow [14].

The assumption for normality has been tested for other 
regional stock markets as well. Ioan and Adrian find that even though the distribution of daily returns for Bucharest stock exchange is not best described by the normality distribution it is not also best described by the Paretian distribution [15]. Chen, Gupta and Troskie confirmed that for Johannesburg stock market [16], Linden for Helsinki stock market [17], Kanellopoulou and Panas for Paris stock market [18], Ushad, Fowdar, Vinesh and Jowaheer for emerging African markets (Botswana, Ghana, Mauritius, Nigeria, South Africa) [19], Haque, Liu and Nisa for Pakistani stock market [20], Herrera, Ortiz and Jesus for Mexican stock market [21] and by Apracio and Estrada for major Scandinavian securities markets [22].

The importance of false assumptions regarding distributions used while developing tools for investing cannot be underestimated. As number of studies have shown the assumption of normal distribution for stock market returns greatly underestimates the impact of fat tails. Olson and $\mathrm{Wu}$ show that assumption on distribution used has great impact on Value at Risk (VaR), a popular measure for risk [23]. By underestimating risk, assets invested in stocks are sensitive to much greater losses than it is assumed. Of course this is applicable both ways - overestimating risk can lead to lower than reasonable risk taking.

Value at risk is also studied by Lee and $\mathrm{Su}$ [24] who find that only by using a distribution function which can take into account skewness together with fat tails one can get more realistic estimates for $\mathrm{VaR}$. Most distributions tend to underestimate the effect of fat tails.

The latter clearly shows that there is no evidence that stock market returns are normally distributed. This will also be tested in current paper for longer time period and different timeframes which is a contribution to existing literature.

The current paper will build a trend following strategy based on the distribution of a certain period and compare the characteristics and results of the strategy with traditional buy-and-hold strategy. This will provide an insight to behavior of market movements and test the overall trendiness of the market.

\section{DATA AND Methodology}

The analysis is performed on the S\&P 500 stock market index which is one of the biggest stock indexes in the world. The data is provided by a public stock market info provider Yahoo! Finance [25]. The analysis is performed on the adjusted stock index (takes into account dividend payments). In total 16088 trading days from the time period $3^{\text {rd }}$ of January 1950 to $6^{\text {th }}$ of December 2013 was taken into account. Daily returns for stock index were calculated by applying the following formula.

$$
r=\frac{P_{t}}{P_{t-1}}-1
$$

where

$r$ - daily return of a stock index;

$P_{t}-$ closing price of a stock index at time $t$;

$P_{t-1}$ - closing price of a stock index at time $t-1$.

The following analysis was performed for multiple different timeframes beginning with a 1 -year timeframe and ending with a 10-year timeframe (with a 1-year step) so that in total 10 different timeframes were analyzed. For each timeframe the subset of daily distributions for a specific time period was formed with a quarterly step in a way that for 1-year timeframe the first subset of data would be from a time period of $3^{\text {rd }}$ of January 1950 to $31^{\text {st }}$ of December 1950 and the second subset of data would be from a time period of April $1^{\text {st }} 1950$ to $31^{\text {st }}$ of March 1951. The same was done for other timeframes as well finally forming a subset of data for a 10-year timeframe firstly from a time period of $3^{\text {rd }}$ of January 1950 to $31^{\text {st }}$ of December 1959 and secondly from a time period of $1^{\text {st }}$ of April 1950 to $31^{\text {st }}$ of March 1960.

Following that methodology we achieve a number of subsets to be analyzed. The total number of subsets to be analyzed in different timeframes is presented in the following Table.

TABLE I: NUMBER OF SUBSETS FOR EACH TIMEFRAME

\begin{tabular}{ll}
\hline \hline Timeframe & Number of subsets in a timeframe \\
\hline 1-year & 250 \\
2-year & 246 \\
3-year & 242 \\
4-year & 238 \\
5-year & 234 \\
6-year & 230 \\
7-year & 226 \\
8-year & 222 \\
9-year & 218 \\
10-year & 214 \\
\hline \hline
\end{tabular}

For each different subset the distribution of daily returns was tested for normality (in total 2320 subsets). For that purpose three different normality tests were performed, more specifically Jarque-Bera test, Kolmogorov-Smirnov test and Shapiro-Wilk test (in total 6960 normality tests).

If the distribution of daily returns inside a subset is not normal then it was tested whether it is skewed towards positive or negative returns. For that purpose the median of the daily returns in a subset was compared with the mean daily return of the subset. The previous trend was then stated as follows:

- If mean return of the subset $>$ median return of the subset then the distribution of returns is skewed to the left and there are more smaller or negative returns than the mean return would suggest. If median return is less than 0 then the returns are distributed accordingly for a downtrend;

- If mean of the subset < median of the subset then the distribution of returns is skewed to the right and there are bigger or more positive returns than the mean return would suggest. If median return is greater than 0 then the returns are distributed accordingly for an uptrend.

For an uptrend it was tested how frequently are quarterly returns (sum of returns in a quarter) positive after a subset that has a positively skewed distribution (indicating that the positive trend would continue). For a downtrend it was tested how frequently are quarterly returns negative after a subset that has a negatively skewed distribution (indicating that the negative trend would continue). If the frequency of trend continuing surpassed $50 \%$ it would indicate that trends 
indeed have a tendency to continue.

Next it is analyzed whether the strength of the trend influences results. The strength of the trend is defined as the relative difference between the absolute value of mean and median. The strength of the trend is defined as follows.

$$
S t=\frac{\mid \text { mean }- \text { median } \mid}{\text { mean }}
$$

where

$S t$ - relative strength of the trend.

It is then analyzed whether the frequency of continuing trend depends on the size of required St by iterating St with different values. It is thus tested whether the distribution of daily returns needs to be heavily skewed to improve the frequency of correct trend continuing or is the relative strength of the previous trend irrelevant. In other terms we discard some of the subsets and distributions as trend since the mean and median returns of a subset are relatively close and a clear trend is not evident.

Finally we analyze whether applying such a trend following strategy leads to lower variance in the portfolio by simulating a trading strategy based on the above and comparing the results with buy-and-hold strategy. For that purpose a Sharpe ratio is calculated for both the trend following strategy and buy-and-hold strategy. Sharpe ratio was calculated based on the return and variance of the strategy and a risk-free rate for which purpose the historical time series of a 10-year US government bond yield was used [25]. For time period preceding 1962 an average monthly yield was used [26].

Analysis is solely performed on the Matlab mathematics package.

\section{RESULtS}

First the normality of the daily returns was analyzed. As it appears none of the normality tests confirmed that daily returns of stock market are normally distributed. The results are the same for all timeframes and periods analyzed (altogether 6960 different time periods). All tests performed on the significance level of 0.05 confirmed that we can reject the null hypothesis that the data is normally distributed. While it was largely expected for shorter timeframes (1 to 3 year periods) it is unexpected that the same is true for a 10 and even for a 60 year period. This confirms the previous empirical findings as it is discussed in the literature overview. This means that the distribution of daily returns is skewed and trendiness is very much a part of the stock market.

Next it was analyzed whether distribution of daily returns can be used while applying a simple trend following strategy where one would buy the stock index if the previous time period has characteristics of an uptrend (median return for a time period is greater than mean return of the same period and it is positive, that is, the distribution is skewed to the right) and one would sell the stock index if the previous time period has characteristics of a downtrend (median return for a time period is lesser than the mean return for the same period and it is negative, that is, the distribution is skewed to the right). The results are presented across different timeframes in the following table.

In the table column "TF" stands for timeframe in years. TF 1 means that a distribution for a time period with a length of 1 year is looked at. When the distribution for the time period has characteristics of an uptrend, the stock index is bought for the following quarter. The time period is shifted by one quarter and if the distribution has again characteristics of an uptrend, the stock index is bought. The stock index is sold if the distribution has characteristics of a downtrend.

"No." in the table presents the number of time periods analyzed. "Buy" stands for the number of time periods where the distribution for the time period had characteristics of an uptrend. "BROI" stands for the total return for the quarters where the index was bought. BROI is calculated by adding together all decimal-wise returns. For timeframe 1 buying signals generated $295 \%$ total profit. "Sell" stands for the number of selling signals for previous time periods that had characteristics of a downtrend. "SROI" stands for the total return for the quarters where the index was sold. "TROI" stands for the total return for both buy and sell signals. "Sharpe" stands for the Sharpe ratio of the strategy. Buy-and-hold strategy for the total 63-year time period had a Sharpe ratio of 1.8. Timeframes that have a bigger Sharpe ratio than buy-and-hold strategy are presented in bold font.

TABLE II: TREND FOLLOWING STRATEGY BY TIMEFRAMES

\begin{tabular}{rrrrrrrr}
\hline \hline TF & No. & Buy & BROI & Sell & \multicolumn{1}{c}{ SROI } & TROI & Sharpe \\
\hline 1 & 250 & 135 & 2.95 & 45 & 1.01 & 3.96 & 1,74 \\
2 & 246 & 152 & 3.39 & 39 & 0.82 & 4.21 & 1,74 \\
$\mathbf{3}$ & $\mathbf{2 4 2}$ & $\mathbf{1 5 8}$ & $\mathbf{2 . 2 9}$ & $\mathbf{3 3}$ & $\mathbf{0 . 8 0}$ & $\mathbf{3 . 0 8}$ & $\mathbf{1 , 9 5}$ \\
$\mathbf{4}$ & $\mathbf{2 3 8}$ & $\mathbf{1 5 7}$ & $\mathbf{2 . 7 9}$ & $\mathbf{3 0}$ & $\mathbf{0 . 6 9}$ & $\mathbf{3 . 4 9}$ & $\mathbf{2 , 3 2}$ \\
$\mathbf{5}$ & $\mathbf{2 3 4}$ & $\mathbf{1 5 3}$ & $\mathbf{2 . 0 1}$ & $\mathbf{2 6}$ & $\mathbf{0 . 7 5}$ & $\mathbf{2 . 7 6}$ & $\mathbf{1 , 8 9}$ \\
6 & 230 & 146 & 1.86 & 16 & 0.60 & 2.46 & 1,60 \\
$\mathbf{7}$ & $\mathbf{2 2 6}$ & $\mathbf{1 4 8}$ & $\mathbf{1 . 5 7}$ & $\mathbf{6}$ & $\mathbf{0 . 2 1}$ & $\mathbf{1 . 7 8}$ & $\mathbf{1 , 8 9}$ \\
$\mathbf{8}$ & $\mathbf{2 2 2}$ & $\mathbf{1 5 6}$ & $\mathbf{2 . 2 4}$ & $\mathbf{0}$ & $\mathbf{0}$ & $\mathbf{2 . 2 4}$ & $\mathbf{1 , 9 5}$ \\
9 & 218 & 154 & 2.37 & 0 & 0 & 2.37 & 1,48 \\
10 & 214 & 164 & 3.40 & 1 & 0.16 & 3.56 & 1,27 \\
\hline \hline
\end{tabular}

Next it was analyzed whether trend strength has any influence on the results. For that purpose distributions that had relatively close values for median and mean return were ignored and index was not bought nor sold. Several values of relative strength were tested. The results are presented in the following table and commented subsequently.

TABLE III: SHARPE RATIOS FOR VARIOUS TIMEFRAMES AND TREND STRENGTHS

\begin{tabular}{lccccccc}
\hline \multicolumn{7}{c}{ Relative strength value } \\
\hline \hline TF & 0.05 & 0.10 & 0.15 & 0.20 & 0.25 & 0.30 & 0.35 \\
\hline 1 & 1,73 & 1,72 & 1,64 & 1,71 & 1,73 & 1,57 & 1,45 \\
2 & 1,72 & 1,78 & $\mathbf{1 , 8 2}$ & $\mathbf{1 , 8 5}$ & $\mathbf{1 , 8 5}$ & 1,73 & 1,77 \\
3 & $\mathbf{1 , 9 5}$ & $\mathbf{1 , 8 6}$ & $\mathbf{2 , 0 0}$ & $\mathbf{2 , 0 2}$ & $\mathbf{2 , 0 5}$ & $\mathbf{1 , 9 6}$ & $\mathbf{2 , 1 5}$ \\
4 & $\mathbf{2 , 4 8}$ & $\mathbf{2 , 4 6}$ & $\mathbf{2 , 6 9}$ & $\mathbf{2 , 6 1}$ & $\mathbf{2 , 6 3}$ & $\mathbf{2 , 7 2}$ & $\mathbf{2 , 7 7}$ \\
5 & $\mathbf{1 , 9 2}$ & $\mathbf{1 , 9 5}$ & $\mathbf{1 , 9 8}$ & $\mathbf{2 , 0 9}$ & $\mathbf{1 , 9 7}$ & $\mathbf{2 , 0 5}$ & 1,60 \\
6 & 1,65 & 1,72 & 1,76 & 1,73 & 1,54 & 1,58 & 1,56 \\
7 & $\mathbf{1 , 8 1}$ & 1,80 & $\mathbf{1 , 9 5}$ & $\mathbf{2 , 0 5}$ & $\mathbf{2 , 3 6}$ & $\mathbf{2 , 5 9}$ & $\mathbf{2 , 5 7}$ \\
8 & $\mathbf{2 , 3 3}$ & $\mathbf{2 , 5 7}$ & $\mathbf{2 , 4 5}$ & $\mathbf{2 , 6 1}$ & $\mathbf{2 , 4 4}$ & $\mathbf{2 , 2 3}$ & $\mathbf{2 , 3 9}$ \\
9 & 1,46 & 1,62 & 1,65 & 1,73 & $\mathbf{2 , 0 8}$ & $\mathbf{2 , 2 5}$ & $\mathbf{2 , 2 5}$ \\
10 & 1,41 & 1,51 & 1,59 & 1,73 & 1,80 & $\mathbf{1 , 9 8}$ & $\mathbf{2 , 4 4}$ \\
\hline \hline
\end{tabular}

Relative strength value 0.05 shows that the absolute difference between mean and median for a certain time period is at least $5 \%$ or more. Relative strength value 0.35 shows that the absolute difference between mean and median 
for a certain time period is $35 \%$ or more. Hence the bigger the relative strength value the more is the distribution for the previous time period tilted to either left or right (stronger downtrend or stronger uptrend). Strength criteria means that if the difference between median and mean is not greater than the strength value then the period is ignored and index is not sold nor bought.

The results lead us to several conclusions. First it can be seen that for most timeframes (especially 3-4 year, 7-8 year and 9-10 year timeframes) the stronger earlier trend leads to higher Sharpe ratio. The reasoning behind it might be related to business cycles and secondly leads us conclude that 3 to 4 year trends and 7 to 8 year trends are good indicators for trend continuing. The results presented in the previous table are also presented in the following figure.

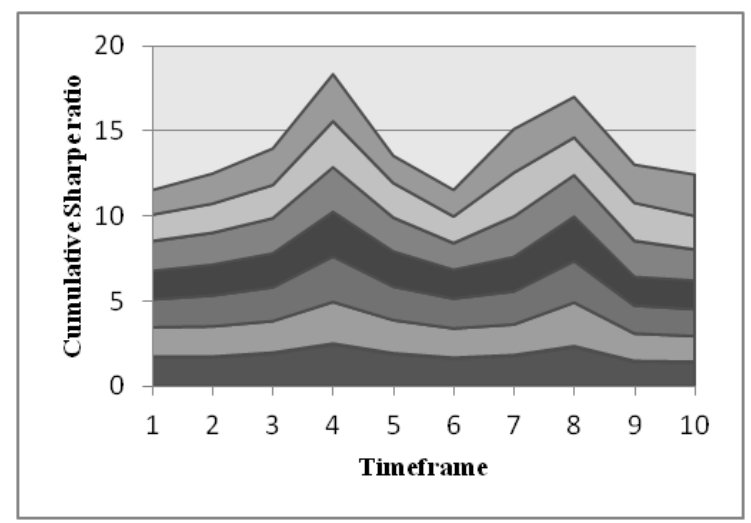

Fig. 1. Cumulative Sharpe ratio for different timeframes.

Thirdly it is also clear that once the strength of trend is taken into account the results are overall better (Sharpe ratios are higher).

The results presented in this paper lead us to believe that markets are by nature trending compared to what the efficient market hypothesis states. Most notably following 3 to 4 year trends and 7 to 8 year trends leads us to better overall risk-reward ratio compared to a simple buy-and-hold strategy. The importance of trends cannot be overstated and since modern portfolio theory relies on random movements and normally distributed daily returns we fear that amongst stock market participants there is a great risk of over- or underestimating the actual Value-at-Risk and modern portfolio tools need to be updated accordingly. This will be the focus of future research for the authors of current paper.

\section{REFERENCES}

[1] H. Markowitz, "Portfolio selection," The Journal of Finance, vol. 7, no. 1, pp. 77-91, 1952.

[2] E. H. Fama, "Efficient capital markets: Review of theory and empirical work," The Journal of Finance, vol. 25, no. 2, pp. 383-417.

[3] L. Bachelier, "The theory of speculation: The origins of modern finance," Princeton University Press, p. 208, 2006.

[4] K. Shah, "The dow theory," Aweshkar Research Journal, vol. 13, no. 1, pp. 77-82, 2012.

[5] B. Mandelbrot, "The variation of certain speculative prices," The Journal of Business, vol. 36, no. 4, pp. 394-394, 1963.

[6] J. Fox, "The myth of the rational market," Harper Collins publisher, p. 390, 2009.

[7] E. F. Fama, "The behavior of stock market prices," Journal of Business, vol. 37, pp. 34-105, January 1965.

[8] J. Teichmoeller, "Distribution of stock price changes," Journal of the American Statistical Association, vol. 66, pp. 282-284, June 1971.

[9] R. R. Officer, "The distribution of stock returns," Journal of the American Statistical Association, vol. 67, no. 340, pp. 807-812, Dec. 1972.

[10] P. D. Praetz, "The distribution of share price changes," The Journal of Business, vol. 45, no. 1, pp. 49-55, Jan. 1972.

[11] I. B. Stadnik, "Explanation of S\&P500 index distribution deviation from a gaussian curve (dynamic financial market model)," Journal of Accounting and Finance, vol. 11, no. 2, pp. 69-77, 2011.

[12] S. T. Rachev, V. S. Stoyanov, A. Biglova, and F. J. Fabozzi, "An empirical examination of daily stock return distributions for U.S. stocks," Data Analysis and Decision Support. Studies in Classification, Data Analysis, and Knowledge Organization, pp. 269-281, 2005.

[13] I. Antoniou, V. V. Ivanov, and P. V. Zrelov, "On the log-normal distribution of stock market data," Physica A, vol. 331, pp. 617-638, 2004.

[14] Y. A. Katz and L. Tian, "Q-Gaussian distributions of leveraged returns, first stopping times, and default risk valuations," Physica A, vol. 392, pp. 4989-4996, 2013.

[15] T. I. Ioan and Z. I. Adrian, "Stock returns and their probabilistic distribution (The bucharest stock exchange case)," Journal of the Faculty of Economics, vol. 3, no. 1, pp. 860-865, 2008.

[16] J. T. Chen, A. K. Gupta, and C. G. Troskie, "The distribution of stock returns when the market is up," Communications in Statistics, Theory and Methods, 2003, vol. 32, no. 8, pp. 1541-1558.

[17] M. Linden, "A model for stock return distribution," International Journal of Finance and Economics, vol. 6, pp. 159-169, 2001.

[18] S. Kanellopoulou and E. Panas, "Empirical distributions of stock returns: Paris stock market 1980-2003," Applied Financial Economics, vol. 18, pp. 1289-1302, 2008.

[19] S. A. Ushad, S. Fowdar, S. R. Vinesh, and M. Jowaheer, "Return distributions: Evidence from emerging african stock exchanges," The IUP Journal of Financial Economics, vol. 6, no. 3, pp. 41-52, 2008.

[20] A. Haque, H. C. Liu, and F. U. Nisa, "Testing the weak form efficiency of Pakistani stock market (2000-2010)," International Journal of Economics and Financial Issues, vol. 1, no. 4, pp. 153-162, 2011.

[21] F. L. Herrera, E. Ortiz, and R. Jesus, "Long memory behavior in the returns of the mexican stock market: Arfima models and value at risk estimation," International Journal of Academic Research in Business and Social Sciences, vol. 2, no. 10, pp. 113-132, 2012.

[22] F. Apracio and J. Estrada, "Empirical distributions of stock returns: Scandinavian securities markets," Statistics and Econometrics Series, vol. 96 , no. 58 , pp. 1-14, 1996.

[23] D. L. Olson and D. Wu, "The impact of distribution on value-at-risk measures," Mathematical and Computer Modelling, no. 58, pp. 1670-1676, 2013.

[24] C. F. Lee and J. B. Su, "Alternative statistical distributions for estimating value-at-risk: theory and evidence," Review of Quantitative Finance and Accounting, vol. 39, no. 3, pp. 309-331, 2012.

[25] Yahoo! Finance. [Online]. Available: http://finance.yahoo.com

[26] R. Shiller. Irrational Exuberance data. [Online]. Available: http://www.irrationalexuberance.com/

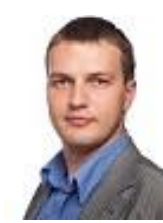

data.
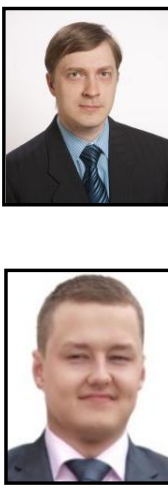

economic data.
A. Teder is currently a PhD student in the University of Tartu and is researching financial markets from the perspective of participants.

His current research focuses on testing various events that influence the price dynamics of a certain financial asset and perform relevant tests. Other areas of interest include pattern recognition and fundamental analysis of economic

P. Sander holds $\mathrm{PhD}$ in economics and is employed as an associated professor in finance at the University of Tartu.

His current research focuses on company valuation in emerging markets, dividend and financing policy, tax-based trading strategies and other financial topics. He has also consulted firms in business valuation cases.

T. Mitt has received bachelor's degree in economics and is researching financial markets from the perspective of participants.

His current research focuses on testing various events that influence the price dynamics of a certain financial asset and perform relevant tests. His other areas of interest include pattern recognition and fundamental analysis of 